\title{
Measurement by EPR Spectroscopy of the Nitrosating Reagent Derived from Nitrite by Formation of Iminoxyl Radicals in the Reaction with 1,3-Dioxo Compounds Such as Acetylacetone. The Use of ${ }^{15} \mathrm{~N}$-Nitrite as an Internal Standard
}

\author{
Carl Lagercrantz*
}

Department of Biomedical Physics, University of Göteborg, Medicinaregatan 11, S-413 90 Göteborg, Sweden

\begin{abstract}
Lagercrantz, C., 1998. Measurement by EPR Spectroscopy of the Nitrosating Reagent Derived from Nitrite by Formation of Iminoxyl Radicals in the Reaction with 1,3-Dioxo Compounds Such as Acetylacetone. The Use of ${ }^{15} \mathrm{~N}$-Nitrite as an Internal Standard. - Acta Chem. Scand. 52: 357-361. (C) Acta Chemica Scandinavica 1998.

The nitrosating reagent of nitrite in acetic acid has been estimated by the formation of iminoxyl radicals $\mathrm{CH}_{3}-\mathrm{C}(=\mathrm{O})-\mathrm{C}=\mathrm{NO}-\mathrm{C}(=\mathrm{O})-\mathrm{CH}_{3}$ in the reaction with the 1,3-dioxo compound acetylacetone. The EPR spectra of the iminoxyl radicals obtained with ${ }^{14} \mathrm{~N}$-nitrite and ${ }^{15} \mathrm{~N}$-nitrite are completely separate, a property which has been utilized for the quantitative estimation of samples of ${ }^{14} \mathrm{~N}$-nitrite by the addition of a known amount of ${ }^{15} \mathrm{~N}$-nitrite as an internal standard. By recording the ratio of the amplitude of the spectrum of ${ }^{14} \mathrm{~N}$ iminoxyl radicals to that of the ${ }^{15} \mathrm{~N}$-iminoxyl radicals, influences from variations of the total amount of iminoxyl radicals inherent to the reaction are eliminated or minimized since these variations will affect the concentration of the ${ }^{14} \mathrm{~N}$ iminoxyl radicals and the ${ }^{15} \mathrm{~N}$-iminoxyl radicals in the same way. The detection limit is set by the background of ${ }^{14} \mathrm{~N}$ nitrite in the ${ }^{15} \mathrm{~N}$ of the internal standard $(1 \%)$. The possible influence of electron spin exchange broadening is discussed.
\end{abstract}

Nitrogen oxides are of general biological interest. Nitric oxide $\mathrm{NO}^{-}$is a physiological substance. ${ }^{1-4} \mathrm{NO}^{+}, \mathrm{NO}_{2}{ }^{\circ}$, $\mathrm{NO}_{2}{ }^{-}, \mathrm{NO}_{3}{ }^{-}$and $\mathrm{N}_{2} \mathrm{O}_{4}$ are toxic substances metabolically derived from nitric oxide or of exogenous origin. $\mathrm{NO}^{\circ}$ and $\mathrm{NO}_{2}{ }^{\circ}$ have an unpaired electron, and are consequently paramagnetic, a property used for their detection. The direct determination of $\mathrm{NO}^{\circ}$ and $\mathrm{NO}_{2}{ }^{\circ}$ by EPR spectroscopy is not possible owing to the short relaxation time which gives rise to broad absorption lines. $\mathrm{NO}^{\circ}$ has been detected by the EPR technique after complex formation with iron(II) and sulfur compounds $s^{5-7}$ or with hemoglobin. ${ }^{8}$ Spin trapping of NO by use of nitroso or nitrone spin traps has not been successful, probably because of the relatively low reactivity of $\mathrm{NO}^{\circ}$. Aminoxyl radicals with the nitrogen derived from $\mathrm{NO}^{\circ}$ have been obtained by formation of nitroso compounds in the reaction between $\mathrm{NO}^{\circ}$ and reactive alkyl radicals followed by the addition of a further reactive alkyl radical. ${ }^{9}$

Nitrogen dioxide $\mathrm{NO}_{2}{ }^{-}$has been measured through

\footnotetext{
* Present address: Änggårdsplatsen 2, S-413 19 Göteborg, Sweden.
}

the aminoxyl radicals $\mathrm{CH}_{3}-\mathrm{SO}_{2}-\mathrm{N}\left(\mathrm{O}^{\circ}\right)-\mathrm{CH}_{3}$ formed in its photochemical reaction with dimethyl sulfoxide. ${ }^{10,11}$

Stable iminoxyl radicals of the type $\mathrm{R}^{1}-\mathrm{C}(=\mathrm{O})-\mathrm{C}=\mathrm{NO}^{-}-\mathrm{C}(=\mathrm{O})-\mathrm{R}^{2}$ are formed in the reaction between a number of 1,3-dioxo compounds such as 2,4-dioxopentane (acetylacetone) or barbituric acid, and tetranitromethane or sodium nitrite. ${ }^{12}$ The EPR spectra of these iminoxyl radicals exhibit large nitrogen coupling constants, i.e., $2.6-3.4 \mathrm{mT}$, and relatively small interactions with other magnetic nuclei of the radical molecules. The reaction with $\mathrm{NO}_{2}{ }^{\circ}$ might be formulated as follows, eqn. (1).

$$
\begin{aligned}
& \mathrm{R}^{1}-\mathrm{C}(=\mathrm{O})-\mathrm{CH}_{2}-\mathrm{C}(=\mathrm{O})-\mathrm{R}^{2} \\
& \stackrel{\mathrm{NO}_{2}{ }_{2} \mathrm{O}}{\longrightarrow} \mathrm{R}^{1}-\mathrm{C}(=\mathrm{O})-\mathrm{C}=\mathrm{NO}^{\cdot}-\mathrm{C}(=\mathrm{O})-\mathrm{R}^{2}
\end{aligned}
$$

Thus, a very high yield of iminoxyl radicals is obtained when $\mathrm{NO}_{2}{ }^{-}$is bubbled through acetylacetone in methanol. ${ }^{12}$ In this reaction the unpaired electron is introduced via the reagent. In the reaction with $\mathrm{NO}^{+}$in an acid solution it seems probable that the diamagnetic 
oxime is formed first, followed by a one-electron oxidation to the iminoxyl radical, eqn. (2).

$$
\begin{aligned}
& \mathrm{R}^{1}-\mathrm{C}(=\mathrm{O})-\mathrm{CH}_{2}-\mathrm{C}(=\mathrm{O})-\mathrm{R}^{2} \\
& \stackrel{\mathrm{NO}^{+}}{\longrightarrow} \mathrm{R}^{1}-\mathrm{C}(=\mathrm{O})-\mathrm{C}=\mathrm{NOH}-\mathrm{C}(=\mathrm{O})-\mathrm{R}^{2} \\
& \mathrm{R}^{1}-\mathrm{C}(=\mathrm{O})-\mathrm{C}=\mathrm{NOHC}(=\mathrm{O})-\mathrm{R}^{2} \\
& \underset{\text { oxidation }}{\longrightarrow} \mathrm{R}^{1}-\mathrm{C}(=\mathrm{O})-\mathrm{C}=\mathrm{NO} \cdot \mathrm{C}(=\mathrm{O})-\mathrm{R}^{2}
\end{aligned}
$$

Reactions (1)-(3) are now used for the estimation of the nitrosating reagent derived from nitrite by use of acetylacetone, i.e., 2,4-dioxopentane, ${ }^{12}$ eqn. (4).

$$
\begin{aligned}
& \mathrm{CH}_{3}-\mathrm{C}(=\mathrm{O})-\mathrm{CH}_{2}-\mathrm{C}(=\mathrm{O})-\mathrm{CH}_{3} \\
& \stackrel{\text { nitrite }}{\longrightarrow} \mathrm{CH}_{3}-\mathrm{C}(=\mathrm{O})-\mathrm{C}(=\mathrm{NO} \cdot)-\mathrm{C}(=\mathrm{O})-\mathrm{CH}_{3}
\end{aligned}
$$

\section{Experimental}

Electron paramagnetic resonance (EPR) spectra were recorded by use of a Varian E-9 spectrometer at $20^{\circ} \mathrm{C}$ with a microwave power of $5 \mathrm{~mW}$ and a $100 \mathrm{kHz}$ modulation amplitude of $0.1 \mathrm{mT}$.

The samples were contained in a flat aqueous solution cell. Hyperfine splitting constants were measured by comparison with the splittings of Fremy's radical $\left(a_{14} \mathrm{~N}=1.3 \mathrm{mT}\right)$. Chemicals were from Aldrich and were used as supplied. $\mathrm{Na}^{15} \mathrm{NO}_{2}\left(99 \%{ }^{15} \mathrm{~N}\right)$ was from ICON Inc.

The radicals were obtained by dissolving water solutions of the ${ }^{14} \mathrm{~N}$-nitrite sample $(1-10 \mu \mathrm{mol})$ and the ${ }^{15} \mathrm{~N}$ nitrite internal standard $(10 \mu \mathrm{mol})$ in $500 \mu \mathrm{l}$ of acetic acid followed by the addition of $50 \mu$ l of acetylacetone. After being gently shaken and warmed at ca. $40^{\circ} \mathrm{C}$ for ca. $30 \mathrm{~s}$, the sample was transferred to the EPR cell and the spectrum recorded. The maximum amplitude of the spectral lines was obtained after ca. 5-8 min. It is essential that the solutions of the ${ }^{14} \mathrm{~N}$ sample and ${ }^{15} \mathrm{~N}$ standard are well mixed in the acetic acid prior to the addition of acetylacetone so that neither of them will be favoured by an inhomogenous solution in the reaction leading to the iminoxyl radicals.

\section{Results and discussion}

Acetylacetone 1 was found to be generally suitable for the quantitative estimation of the nitrosating reagent derived from nitrite since it dissolves freely in acetic acid. Furthermore the EPR spectrum of the iminoxyl radical formed in the reaction, i.e., $\mathbf{2}$ is relatively simple. One single geometric isomer is present due to the symmetry of the radical. Hyperfine interactions with the hydrogens of the two methyl groups are very narrow and do not give rise to disturbing interferences with the use of a relatively large $100 \mathrm{kHz}$ modulation $(0.1 \mathrm{mT})$.

Figure 1 shows the EPR spectrum of the iminoxyl radical 2, obtained by nitrosation of 1 with sodium nitrite [eqn. (4)] in acetic acid. In this case the radicals appeared without addition of an oxidizing reagent. It is not possible to determine whether the nitrosation involves $\mathrm{NO}^{+}$with intermediate formation of the corresponding oxime followed by oxidation to the iminoxyl radical, eqns. (2), (3), or a direct addition of $\mathrm{NO}_{2}{ }^{\circ}$, eqn. (1). $\mathrm{NO}^{-}$might be formed via eqn. (5).

$3 \mathrm{HNO}_{2} \rightarrow 2 \mathrm{NO}+\mathrm{HNO}_{3}+\mathrm{H}_{2} \mathrm{O}$

Subsequently $\mathrm{NO}_{2}{ }^{\circ}$ is formed by oxidation of $\mathrm{NO}^{\cdot}$ by dissolved oxygen. It is possible that nitrogen dioxide can act as the oxidizing reagent in the formation of the iminoxyl radical from the intermediate oxime, eqn. (3).

The spectrum of Fig. 1(a) was obtained with a mixture of $10 \mu \mathrm{mol}$ of $\mathrm{Na}^{14} \mathrm{NO}_{2}$ and $10 \mu \mathrm{mol}$ of $\mathrm{Na}^{15} \mathrm{NO}_{2}$. The coupling constants of the spectral component obtained with $\mathrm{Na}^{14} \mathrm{NO}_{2}$ were: $a_{{ }_{14} \mathrm{~N}}=2.70 \mathrm{mT}(1 \mathrm{~N})$, and with $\mathrm{Na}^{15} \mathrm{NO}_{2}: a_{15}=1.4 \times 2.70=3.78 \mathrm{mT}(1 \mathrm{~N})$, where the factor 1.4 is the ratio between the coupling constants of ${ }^{15} \mathrm{~N}$ and ${ }^{14} \mathrm{~N}$. The large coupling constants make it possible to observe the iminoxyl spectra obtained in the reaction with $\mathrm{Na}^{14} \mathrm{NO}_{2}$ and $\mathrm{Na}^{15} \mathrm{NO}_{2}$ simultaneously without any overlaps. This spectral distribution is now used for the estimation of the nitrosating reagent derived from ${ }^{14} \mathrm{~N}$-nitrite with added ${ }^{15} \mathrm{~N}$-nitrite as an internal standard by measuring the amplitudes. Table 1(a) shows the amplitudes of the spectral components and their ratios at different times after mixing of the reagents. After passing through a maximum the radical amount slowly decreases. However, the ratio of the amplitudes of the ${ }^{15} \mathrm{~N}$ to the ${ }^{14} \mathrm{~N}$ spectra remains fairly constant as expected. Therefore a quantitative estimation of the amount of ${ }^{14} \mathrm{~N}$-nitrite of a sample could be performed by a continuous reference to the added internal standard of ${ }^{15} \mathrm{~N}$-nitrite in spite of the change of concentration of the iminoxyl radicals. The amounts of ${ }^{14} \mathrm{~N}$ and ${ }^{15} \mathrm{~N}$ iminoxyl radicals were empirically considered to be represented by the sum of the peak-to-peak amplitudes of the spectral components of ${ }^{14} \mathrm{~N}$ and ${ }^{15} \mathrm{~N}$ spectra.

Table 1. (a) Amplitudes of the spectral component and their ratios at different times after mixing of the reagents.

\begin{tabular}{lcc}
\hline & $A\left(M_{1}=+1 / 2\right) /$ & $A\left(M_{1}=-1 / 2\right) /$ \\
Time after mixing & $A\left(M_{1}=+1\right)$ & $A\left(M_{1}=-1\right)$ \\
\hline $5 \mathrm{~min}$ & $126 / 51=2.47$ & $115 / 46=2.50$ \\
$30 \mathrm{~min}$ & $88 / 36=2.44$ & $81 / 32=2.5$ \\
\hline
\end{tabular}

(b) The experimental ${ }^{14} \mathrm{~N} /{ }^{15} \mathrm{~N}$ ratios obtained with $5 \mu \mathrm{mol}$ of ${ }^{14} \mathrm{~N}$ and $10 \mu \mathrm{mol}$ of ${ }^{15} \mathrm{~N}$ nitrite. The results obtained with three different experiments.

\begin{tabular}{lll}
\hline$A\left(M_{1}=+1\right)+A\left(M_{1}=0\right)$ & $A\left(M_{1}=+1 / 2\right)$ & \\
$+A\left(M_{1}=-1\right)$ & $+A\left(M_{1}=-1 / 2\right)$ & Ratio \\
\hline 109 & 184 & 0.59 \\
246 & 418 & 0.60 \\
258 & 437 & 0.60 \\
\hline
\end{tabular}



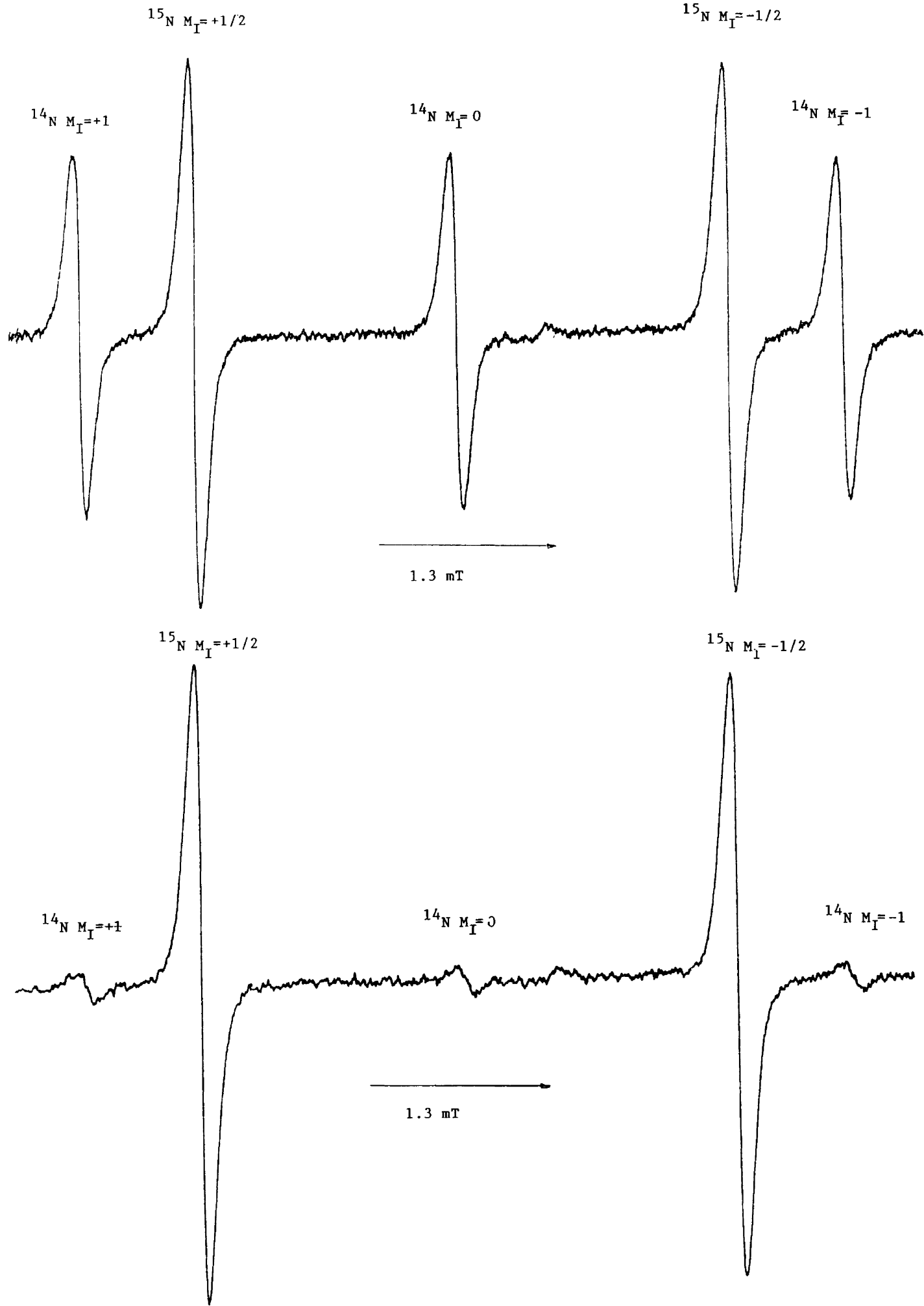

Fig. 1. (a) The EPR spectrum of the iminoxyl radicals formed in the reaction between $50 \mu$ of acetylacetone dissolved in $0.5 \mathrm{ml}$ of acetic acid and a water solution containing $10 \mu \mathrm{mol}$ of $\mathrm{Na}^{14} \mathrm{NO}_{2}$ and $10 \mu \mathrm{mol}$ of $\mathrm{Na}^{15} \mathrm{NO}_{2}$. The spectrum was recorded ca. $10 \mathrm{~min}$ after mixing of the reagents. Spectrometer settings: microwave power $5 \mathrm{~mW}$; modulation amplitude $0.1 \mathrm{mT}$; time constant $0.3 \mathrm{~s}$; receiver gain $1.6 \times 10^{2}$; scanning speed $0.45 \mathrm{mT} \mathrm{min}{ }^{-1}$. The ratio of the amplitudes of the ${ }^{14} \mathrm{~N} /{ }^{15} \mathrm{~N}$ spectra was evaluated from the spectral amplitudes, i.e., by eqn. (6), and was ca. 1.0. (b) The EPR spectrum of the iminoxyl radical obtained with $0.1 \mu \mathrm{mol}$ of ${ }^{14} \mathrm{~N}$ nitrite and $2 \mu \mathrm{mol}$ of ${ }^{15} \mathrm{~N}$ nitrites. Spectrometer settings: microwave power $5 \mathrm{~mW}$; modulation amplitude $0.1 \mathrm{mT}$; time constant $1 \mathrm{~s}$; receiver gain $5 \times 10^{3}$; scan time $0.225 \mathrm{mT}^{\mathrm{min}^{-1}}$. The amplitude ratio of ${ }^{14} \mathrm{~N} /{ }^{15} \mathrm{~N}$ spectra is ca. 0.08 . 
The nitrosating content of the test sample was evaluated by multiplying the amount of ${ }^{15} \mathrm{~N}$-nitrite added to the reaction mixture by the ratio $r$ between the sum of the peak-to-peak amplitudes of the three components of the ${ }^{14} \mathrm{~N}$ spectrum to the sum of the amplitudes of two components of the ${ }^{15} \mathrm{~N}$ spectrum respectively, assuming a constant and the same linewidth to all lines, eqn. (6).

$$
\begin{aligned}
& {\left[A\left(M_{1}=+1\right)+A\left(M_{1}=0\right)+A\left(M_{1}=-1\right)\right] /} \\
& {\left[A\left(M_{1}=+1 / 2\right)+A\left(M_{1}=-1 / 2\right)\right]}
\end{aligned}
$$

Figure 2 shows this ratio plotted against added amounts of ${ }^{14} \mathrm{~N}$-nitrite between 15 and $1 \mu \mathrm{mol}$. The internal standard of ${ }^{15} \mathrm{~N}$-nitrite was $10 \mu \mathrm{mol}$. From this relationship, and the spectrum observed with $0.1 \mu \mathrm{mol}$ of ${ }^{14} \mathrm{~N}$-nitrite and $2 \mu \mathrm{mol}$ of ${ }^{15} \mathrm{~N}$-nitrite, Fig. 1(b), the detection limit seems to be ca. $0.05 \mu \mathrm{mol}$ of nitrite $\left(5 \times 10^{-8} \mathrm{~mol}\right)$. However, the formal limit is set initially by the percentage ${ }^{14} \mathrm{~N}$ content of the ${ }^{15} \mathrm{~N}$ standard which was $1 \%$ (cf. Experimental). For the present case with an internal standard of $10 \mu \mathrm{mol}$ this means that the detection limit would be $1 \%$ of $10 \mu \mathrm{mol}$, i.e., $10 \times 10^{-8} \mathrm{~mol}$, and for the experiment of Fig. 1(b), $2 \times 10^{-8} \mathrm{~mol}$. Evidently this limit can be decreased by subtraction of the ${ }^{14} \mathrm{~N}$ background and by further reduction of the internal standard. Table 1 (b) shows the reproducibility of the method when the same mixture of sample and internal standard was used in three consecutive experiments.

Electron spin exchange broadening might influence on the results. The broadening is related to the square of the radical concentration. ${ }^{14}$ Therefore, it is expected that the measured ratio of the amplitudes corresponding the sample ${ }^{14} \mathrm{~N}$ iminoxyl radicals to that of the internal standard, eqn. (6), is higher than the real value when the radical concentration of the internal standard is high

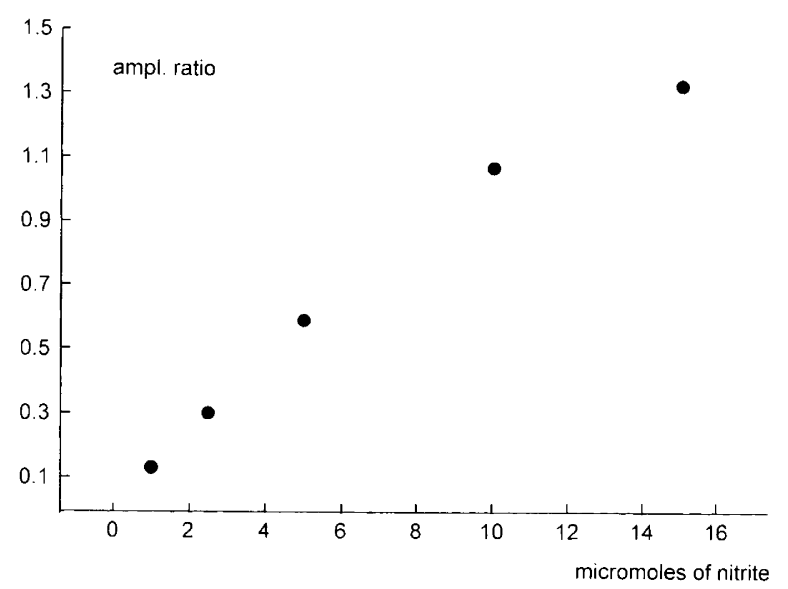

Fig. 2. The amplitude ratio between the ${ }^{14} \mathrm{~N} /{ }^{15} \mathrm{~N}$ spectra plotted against added amounts of ${ }^{14} \mathrm{~N}$ nitrite. Each sample contained $10 \mu \mathrm{mol}$ of ${ }^{15} \mathrm{~N}$ nitrite as an internal standard. The amplitude ratio was evaluated by the ratio $\left[A\left(M_{1}=+1\right)\right.$ $\left.+A\left(M_{1}=0\right)+A\left(M_{1}=-1\right)\right] /\left[A\left(M_{1}=+1 / 2\right)+A\left(M_{1}=-1 / 2\right)\right]$, eqn. (6). Added amounts of ${ }^{14} \mathrm{~N}$ nitrite were between 15 and $1 \mu \mathrm{mol}$. Each value is the mean value of three different measurements. The background of ${ }^{14} \mathrm{~N}$ in the internal standard was not subtracted. compared with that of the ${ }^{14} \mathrm{~N}$ sample. A quantitative estimation of the broadening effect is not possible since it requires information of the radical concentration which is not known. Furthermore it is not clear whether or not electron spin exchange broadening might take place even between the ${ }^{14} \mathrm{~N}$ and ${ }^{15} \mathrm{~N}$ iminoxyl radicals, a situation which would eliminate differences of broadening between the two radical species. Consequently, possible effects of this sort of broadening will be minimized by use of an internal standard concentration not too different from that of the sample, and the use of adequate standard curves (cf. Fig. 2). Access to a spectrometer with double integration would have eliminated complications of broadening. However, such facilities were not at hand.

\section{Conclusions}

The aim of the experiments described was to develop a method for the determination of nitrite in water solutions.

The nitrosation of 1,3-dioxo compounds such as acetylacetone leading to iminoxyl radicals seems to be a complex reaction. It can be achieved by reaction between tetranitromethane in methanol-pyridine. ${ }^{12}$ tert-butyl nitrite in methanol, or nitrite in an acid medium. Irrespective of the mechanism, ionic or radical, the present experiments can be used to estimate the ability of nitrite in acetic acid to produce iminoxyl radicals derived from acetylacetone. The use of ${ }^{15} \mathrm{~N}$-nitrite as an internal standard seems to eliminate variations of the radical content with time inherent in the nitrosating reaction of acetylacetone. Increases and decreases will affect the ${ }^{14} \mathrm{~N}$ and ${ }^{15} \mathrm{~N}$ iminoxyl radicals identically leaving their ratio constant. This statement proscribes that the recording of the absorption lines of ${ }^{14} \mathrm{~N}$ and the corresponding ${ }^{15} \mathrm{~N}$ lines is performed within a close period of time, and that no isotope effects will influence the reaction rates of ${ }^{14} \mathrm{~N}$ and ${ }^{15} \mathrm{~N}$ systems. The influence of a ${ }^{14} \mathrm{~N}$ background which originates from the presence of ${ }^{14} \mathrm{~N}$-nitrite present in the ${ }^{15} \mathrm{~N}$ standard will be minimized by subtraction and use of an internal standard with as low a concentration as possible. Possible effects of electron spin exchange broadening will be minimized by adequate standard curves (cf. Fig. 2), and an internal standard concentration not too different from that of the samples.

Acknowledgements. This work was supported by grants from Adlerbertska Forskningsfonden and The Royal Society of Arts and Sciences in Gothenburg.

\section{References}

1. Furchgott, R. F. and Vanhoute, P. M. FASEB J. 3 (1989) 2007.

2. Moncada, S., Palmer, R. M. and Higgs, E. A. Biochem. Pharmacol. 38 (1989) 1709.

3. Ignarro, J. L. Biochem. Pharmacol. 41 (1991) 485.

4. Stamler, I. S., Singel, D. J. and Loscalzo, J. Science 258 (1992) 1898 
5. MacDonald, C. C., Philips, W. D. and Mowe, H. F. J. Am. Chem. Soc. 87 (1965) 3319.

6. Archer, S. FASEB J. 7 (1993) 349.

7. Norby, S. W., Weyhensmeyer, J. A. and Clarkson, R. B. Free Radicals Biol. Med. 22 (1997) 1.

8. Wennmalm, A., Lanne, B. and Petersson, A. S. Anal. Biochem. 187 (1990) 359.

9. Lagercrantz, C. Free Radical Res. Commun. 19 (1993) 387.

10. Lagercrantz, C. Acta Chem. Scand. 23 (1969) 3259.

11. Pace, M. D. and Kalayanaraman, B. Free Radical Biol. Med. 15 (1993) 337.
12. Lagercrantz, C. and Torssell, K. Ark. Kemi 29, No. 18 (1968) 203.

13. Williams, D. L. H. Nitrosation, Cambridge University Press, Cambridge 1988.

14. Wertz, J. E. and Bolton, J. R. Electron Spin Resonance. Elementary Theory and Practical Applications, McGrawHill, New York 1972, Ch. 9.

Received May 22, 1997. 